\title{
La noción de ley en Suárez y Locke
}

\author{
The notion of the law in Suárez and Locke
}

\author{
LEOPOLDO JOSÉ PRIETO LÓPEZ*
}

\begin{abstract}
Resumen: Se puede afirmar que la concepción voluntarista de la ley en Locke es típicamente moderna. El empleo de un léxico que enfatiza el elemento volitivo como esencia de la ley tiene su origen en teorías antropológicas, jurídicas y teológicas tardomedievales, de las que Suárez es el principal vehículo en su transmisión a la modernidad. Sea directa, sea indirectamente, el influjo de la concepción suareciana de la ley sobre Locke es incontestable. El artículo indaga, finalmente, la secuencia histórica Suárez-Grotius-Locke en la búsqueda del hilo conductor del voluntarismo de dichos autores y replantea diversamente de como habitualmente es entendida la fórmula empleada por Grotius sobre la validez de la ley natural, a saber «etiamsi daremus non esse Deum» («etsi Deus non daretur»), cuyo verdadero sentido es indicar la relativa autonomía de la ley natural respecto de la voluntad divina.

Palabras clave: Suárez, Grotius, Culverwell, Locke; Gregorio de Rímini, Gabriel Biel; nominalismo, voluntarismo; ley positiva, ley natural; Tractatus de legibus ac de Deo legislatore, Essays on natural law, De iure belli ac pacis.
\end{abstract}

\begin{abstract}
It can be affirmed that the voluntarist sense of Locke's notion of law is typically modern. The use of a lexicon emphasizing the volitional element as the essence of law has its origin in anthropological, juridical and theological theories of the Late Middle Ages, of which Suárez is the principal vehicle of transmission to modernity. Whether directly or indirectly, the influence of Suárez's concept of law on Locke is indisputable. The last part of this article investigates the historical sequence Suárez-Grotius-Lock searching for a common, developmental thread in the voluntarism of said authors, and proposes a way to understand Grotius's expression regarding the validity of natural law, "etiamsi daremus non esse Deum", diverse from how it is habitually understood, whose real meaning is to indicate the relative autonomy of natural law with respect to the divine will.

Key words: Suárez, Grotius, Culverwell, Locke; Gregoy of Rimini, Gabriel Biel; nominalism, voluntarism; positive law, natural law; Tractatus de legibus ac de Deo legislatore, Essays on natural law, De iure belli ac pacis.
\end{abstract}

En este artículo nos disponemos a estudiar el concepto de ley en Locke, así como el influjo, directo o indirecto, ejercido por Suárez y algunos otros autores sobre este autor. De otro lado, dado que Locke no ha tratado sistemáticamente de la noción de ley más que a

Fecha de recepción: 24/09/2015. Fecha de aceptación: 30/07/2016.

* Leopoldo José Prieto López es profesor en la Universidad Francisco de Vitoria Su e-mail es 1prieto7@gmail. com. Actualmente trabaja en las dos siguientes líneas de investigación: los presupuestos medievales del pensamiento moderno, especialmente en metafísica, teoría del conocimiento y teoría política; y el pensamiento de Locke, con especial referencia a la temática religiosa, en particular a la Carta sobre la tolerancia y La razonabilidad del cristianismo, tal como es presentado en las Escrituras. Algunas de sus últimas publicaciones son: "Ockham, Suárez y Descartes: transición de las noéticas tardomedievales a la filosofía moderna": Anales del Seminario de Historia de la filosofía 33/1 (2016) 33-57; "La teología de John Locke": Revista española de teología 72/1 (2012) 29-84. 
propósito de la ley natural, nuestro acercamiento al concepto lockiano de ley no tiene más remedio que partir del concepto de ley natural expuesto en los Ensayos sobre la ley natural.

Pocos aspectos como el argumento de este artículo reflejan tan claramente, en mi opinión, el influjo de un pensador español allende nuestras fronteras en los albores de la modernidad. No sólo a Locke, en quien nos centraremos especialmente, sino también a Grotius, y con ellos al naciente orden jurídico moderno europeo e internacional alcanzan los ecos de la obra jurídico-política de Suárez, como es pacíficamente reconocido desde hace tiempo por los estudiosos.

Francisco Suárez, tras una larga carrera académica como teólogo transcurrida fundamentalmente en Alcalá de Henares, Roma y Salamanca, se trasladó a Portugal en 1597. Allí, en Coimbra, hasta 1617, transcurrieron los últimos años de su vida. En este tiempo trató diversas cuestiones teológicas y canónicas. Pero sobre todo se dedicó al estudio de sus grandes intereses jurídicos y políticos, expuestos en sus dos últimas grandes obras: el Tractatus de legibus ac de Deo legislatore (1612) y la Defensio fidei catholicae adversus anglicanae sectae errores (1613). De ellas la que más interesa a nuestro propósito es la primera, donde aparece una noción de ley de capital importancia para la modernidad.

Michel Bastit ha llamado la atención sobre la crucial importancia de Suárez y del De Legibus en el nacimiento del concepto moderno de la ley. En opinión de este autor, los puntos principales de la doctrina nominalista de la ley se han desarrollado y transmitido a la época moderna a través fundamentalmente de Suárez. La obra de Suárez ha venido a ser así el canal principal por el que se han transmitido al pensamiento jurídico moderno los principios voluntaristas de Escoto y Ockham. En esta transmisión el pensamiento jurídico de Francisco Suárez aparece como la gran síntesis que intenta conciliar, en un imposible eclecticismo, un cierto número de elementos de la tradición realista tomista y aristotélica con la aportación del pensamiento nominalista ${ }^{1}$.

El artículo procede del siguiente modo. Después de exponer sucintamente la noción de ley de Suárez, se prosigue con el análisis de dicha noción en los Ensayos sobre la ley natural de Locke. Al modo escolástico estudia Locke primero la cuestión de la existencia de la ley natural, resuelta afirmativamente como conclusión de cinco argumentos. Posteriormente estudia la cuestión de la esencia, afrontada tanto nominal como realmente. Aquí, en la definición real de la esencia de la ley, Locke muestra el característico voluntarismo, siempre moderado, de su noción de ley. En efecto, la esencia de la ley natural consiste -dice Lockeen ser «la disposición de la voluntad divina [...] que se expresa con la formulación de un mandato o de una prohibición». Descubierta la orientación voluntarista de la noción de ley en Locke, se analiza expresamente dicha cuestión. Pero como el voluntarismo es una nota común a la mayor parte de los tratadistas jurídicos modernos, no sólo a Suárez y Locke, se estudian así algunos aspectos de la obra de Grotius, coincidentes con el voluntarismo suareciano y lockiano. En este momento se aprovecha la ocasión para hacer un excursus sobre la expresión de Grotius, frecuentemente malinterpretada, sobre la validez de la ley natural etiamsi daremus non esse Deus (popularizada en la fórmula etsi Deus non daretur), que además de confirmar la concepción igualmente voluntarista de ley del filósofo holandés, está

1 Cf. M. Bastit, Naissance de la loi moderne: la pensée de la loi de Saint Thomas a Suárez, PUF, Paris 1990, 307. 
pensada para dar a conocer la relativa autonomía de la ley natural como fundamento de la obligatoriedad de la ley positiva. Finalmente, retornando a Locke, el artículo concluye con el estudio del fundamento de la obligatoriedad de la ley según Locke, que viene a confirmar, si aún hiciera falta, la orientación voluntarista ya expuesta.

\section{El concepto de ley en Suárez}

El Tractatus de legibus ac de Deo legislatore, o simplemente el De Legibus, como suele citarse la gran obra de filosofía del derecho de Suárez, salió a la luz en 1612. La obra contiene un concepto de ley que todas las generaciones de juristas han estudiado con detenimiento. A diferencia de Tomás de Aquino, para hacer una comparación clásica, para quien la esencia de la ley es una ordenación de la razón (lo que permite de antemano excluir de la categoría de ley toda norma que atente contra el orden de la naturaleza y de la razón²), Suárez propone un concepto de ley ciertamente diferente, como «el acto de la voluntad justa y recta mediante el cual el superior quiere obligar al inferior a hacer una determinada cosa $»^{3}$. Y como esta voluntad debe serle conocida al súbdito, añade Suárez, «con el nombre de ley se significa tanto el imperio externo como el signo ostensivo de la voluntad del que manda» ${ }^{4}$. El léxico del De legibus, como puede verse, pone un claro énfasis sobre la voluntad en la definición de ley.

Ha pasado ya mucho tiempo desde que Rommen advirtiera que el verdadero fundamento de la teoría jurídica y política de Suárez se encontraba en su filosofía y más en concreto en su metafísica y en su teoría del conocimiento. Una teoría del conocimiento como la del pensador granadino, que ponía el acento en el conocimiento intelectual directo (es decir, no abstractivo) de las sustancias singulares, fundada sobre las bases de una metafísica inequívocamente escotista, se correspondía con la tendencia a subrayar la voluntad, la libertad y la acción humanas, que operan siempre en el campo de lo singular y concreto. Sin duda que el influjo de Escoto, especialmente visible en la teoría suareciana de la actualidad de la materia prima (dotada, al menos un acto entitativo, aunque no formal) ${ }^{5}$, de donde a su vez procedía la tesis de la individualización de cada entidad por sí misma, modificaba el tomismo tradicional, provocando en el campo jurídico y social una acentuación de la dimensión individual y personal ${ }^{6}$.

2 T. DE Aquino, Summa theologiae, I-II ${ }^{\mathrm{ae}}$, en «S. Thomae Aquinatis, Doctoris Angelici, Opera omnia iussu impensaque Leonis XIII P. M. edita, t. VII» (ex Typographia Polyglotta Vaticana, Romae 1892), q. 90, a. 4, co., donde Tomás de Aquino define la ley como «quaedam rationis ordinatio ad bonum commune, ab eo qui curam communitatis habet, promulgata» («una ordenación de la razón dirigida al bien común, promulgada por quien tiene el cuidado de la comunidad»).

3 F. SuÁrez, De Legibus, en «R.P. Francisci Suarez e Societate Jesu Opera Omnia, t. V», (apud Ludovicum Vivès, Parisiis 1856), 1, 5, 24: «[...] legem in ipso legislatore esse actum voluntatis justae et rectae, quo superior vult inferiorem obligare ad hoc vel illud faciendum». Traducción y cursivas son propias.

4 F. SuÁrez, De legibus, 1, 5, 25: «Ultimo vero assero respiciendo ad nominis legis impositionem, videri prius positum, ad significandum externum imperium et signum ostensivum voluntatis praecipientis». Traducción y cursivas son propias.

5 Cf. L. Prieto, Suárez y el destino de la metafísica: de Avicena a Heidegger, BAC, Madrid 2013.

6 Cf. H. A. Rommen, «Variaciones sobre la filosofía jurídica y política de Francisco Suárez»: Pensamiento 4 (1948), 493-498, 494. 
$\mathrm{Al}$ énfasis puesto en la voluntad, tan característico de la concepción suareciana de la ley, se ha dirigido frecuentemente el reproche de voluntarista. En la cuestión de la esencia de la ley, determinando si ésta consiste en un acto del intelecto o bien en un acto de la voluntad, los tomistas nunca han dudado en atribuirle un carácter intelectual, aunque de orientación práctica, claro está, mientras que los escotistas han subrayado constantemente la importancia del aspecto volitivo (o imperativo). El intento de Suárez de eludir la alternativa adoptando una tercera tesis, según la cual la ley es un acto en el que concurren ambas facultades, es claro que, dada la relevancia que en dicha definición se concede a la voluntad legisladora, su opinión era una modalidad de la adoptada por los escotistas ${ }^{7}$. Los discípulos de Suárez siempre han objetado que el peligro de voluntarismo era contrarrestado mediante el uso en la definición de ley de los adjetivos de justa y recta aplicados al sustantivo voluntad. Sea cual fuere la conclusión a la que se llegue en esta polémica, parece claro que para Suárez la ley no se agota en la presentación de un dato positivo encuadrado en un orden racional, sino que necesariamente tiene que ser acompañada del acto imperativo de una voluntad, puesto que el mandato y la obligación subsiguiente son los que hacen de una disposición normativa una ley ${ }^{8}$ Y éste es precisamente el elemento de la teoría suareciana que ha pasado a la teoría moderna de la ley, y en particular a la de Locke, como vamos a ver enseguida.

En definitiva, bajo la inspiración de la escuela nominalista, Suárez ha invertido el planteamiento tomista al considerar como fundamento de la ley no un acto de la razón, sino de la voluntad, atribuyendo así un valor tanto a la voluntad como a la libertad humanas desconocido para los autores medievales. Para Suárez la ley no es una norma universal de justicia, sino el resultado de la decisión del legislador. En congruencia con esta noción de ley, cuya esencia es puesta en una decisión de la voluntad, las nociones fundamentales de su filosofía política (como las de comunidad política, delegación del poder, constitución del Estado, etc.) eran vistas a la luz de una antropología de signo moderadamente voluntarista. Precisamente éste era el objeto de la última obra de Suárez, la Defensio fidei (1613), en particular de su núcleo teórico, que es el libro III.

Hasta aquí Suárez y el concepto moderno de ley a cuya forja contribuyó tan decisivamente el filósofo granadino. Pasemos ahora a estudiar el concepto de ley en John Locke.

\section{El concepto de ley en Locke}

Las obras más importantes de Locke a propósito del concepto de ley son los Dos Tratados sobre el gobierno civil (1689) y los Ensayos sobre la ley natural (1664). En ambas obras se afronta el estudio de la noción de ley, tanto natural como positiva, dando una especial relevancia a la ley natural como límite esencial de la fuerza vinculante de la ley positiva. En ambas obras aparecen repetidas veces indicaciones sobre la naturaleza, fines y límites de la ley positiva siempre en referencia a la ley natural, fuente última de obligatoriedad jurídica según Locke.

7 Cf. F. SuÁREZ, De legibus, 1, 5, 23.

8 Cf. J. A. Maravall, «I pensatori spagnoli del secolo d'oro», en L. Firpo (ED.), Storia delle idee politiche, economiche e sociali, vol. III, Utet, Torino 1989, 611-693, 681. 
Como se ha dicho antes, este estudio pretende poner de manifiesto la recepción, directa o indirecta, de algunas ideas de Suárez sobre la naturaleza de la ley por parte de Locke. El aspecto primordial de la teoría de la ley de Suárez presente en la obra de Locke es la impronta voluntarista, tan característica de la concepción moderna de ley.

Los Dos Tratados sobre el Gobierno son una obra compuesta de dos partes. La primera, de carácter polémico, contiene la crítica de Locke a la doctrina absolutista del derecho divino de los reyes, tal como se expresa en El Patriarca (1642) de Robert Filmer. La segunda expone la doctrina sobre el origen, naturaleza, fin y límites del poder político, del cual la ley positiva es su vehículo primordial. Por lo que aquí interesa hay que decir que Locke se acogía en esta obra a una tradición de pensamiento político que, por medio de Richard Hooker, llegaba hasta las fuentes del constitucionalismo medieval, cuyo fundamento último descansaba en la ley natural ${ }^{9}$. En este sentido Locke no es un autor moderno. Precisamente el punto focal de los Dos Tratados sobre el Gobierno es la indiscutida prevalencia de la ley natural sobre la ley positiva, aunque el tratamiento explícito dedicado a esta última resulta más bien exiguo, limitándose a exponer en los capítulos XI y XII del Segundo Tratado una sucinta doctrina sobre el alcance del poder legislativo y su relación con los otros poderes del Estado, respectivamente.

En el capítulo segundo del Segundo tratado sobre el Gobierno civil, dedicado al estado de naturaleza, se contiene una breve descripción del contenido de la ley natural. A propósito del derecho de punición (que, conforme a dicha ley, reside en manos de los particulares mientras la sociedad política no ha sido constituida) explica Locke en un texto decisivo que la ley natural es no sólo el fundamento de justicia de la legislación positiva, sino el criterio de interpretación al que se ha de acoger el juez en la aplicación de las leyes positivas. El texto dice así:

Es cierto que existe esta ley [es decir, la ley natural], y que es inteligible y clara para una criatura racional [...] tanto como lo son las leyes positivas de las sociedades políticas; o incluso más que éstas, porque es más fácil entender la razón que las fantasías y las intrincadas invenciones de los hombres, que persiguen intereses contrarios y ocultos, celados bajo las palabras, pues de esta suerte son gran parte de las leyes civiles de algunos países, las cuales son justas únicamente en cuanto fundadas en la ley natural, por medio de la cual deben ser aquéllas reguladas e interpretadas ${ }^{10}$.

Pero donde verdaderamente ha realizado Locke un estudio completo y sistemático del tema que nos ocupa es en los Ensayos sobre la ley natural ${ }^{11}$. Pasemos, pues, al estudio de

9 Cf. G. SAbine, Historia de la teoría política, FCE, México 2006, 402-403.

10 J. Locke, Segundo tratado sobre el gobierno civil, en «The Works of John Locke in Nine Volumes» (12 ${ }^{\mathrm{a}}$ ed.), vol. IV, Rivington, London 1824, II, 2, 12: «Yet it is certain there is such a law [law of nature], and that too, as intelligible and plain to a rational creature [...] as the positive laws of commonwealths, nay possibly plainer; as much as reason is easier to be understood, than the fancies and intricate contrivances of men, following contrary and hidden interests put into words; for so truly are a great part of the municipal laws of countries, which are only so far right, as they are founded on the law of nature, by which they are to be regulated and interpreted». La traducción es mía.

11 Cf. J. Locke, Essays on the Law of Nature. The Latin Text with a Translation, Introduction and Notes (ed. W. von Leyden), at the Clarendon Press, Oxford 1954, repr. 2007. Citaremos esta obra como Eln. Aunque existe 
esta obra. Los Ensayos sobre la ley natural fueron escritos en latín en un período que va desde el 1660 hasta el 1664. Inéditos a la muerte de Locke, se conservaron en la Lovelace Collection $^{12}$, depositada en 1942 en la Bodleian Library, de la Universidad de Oxford, que encargó a W. von Leyden los trabajos de traducción al inglés y anotación crítica, publicados en 1954 por Clarendon Press de Oxford. La obra en cuestión se divide en ocho secciones que, expuestas al modo escolástico, se refieren a la existencia de la ley natural ( $\left.\mathrm{sec} .1^{\mathrm{a}}\right)$, su cognoscibilidad (sec. $2^{\mathrm{a}}$ a $5^{\mathrm{a}}$ ), su obligatoriedad $\left(\mathrm{sec} .6^{\mathrm{a}} \mathrm{y} 7^{\mathrm{a}}\right)$ y su fundamento $\left(\sec .8^{\mathrm{a}}\right)^{13}$.

En contraste con el pesimismo antropológico y el positivismo jurídico que impregnan tan profundamente la obra de Thomas Hobbes, los Ensayos sobre la ley natural (escritos precisamente como respuesta a las recién publicadas obras de Hobbes: Leviathan [1651], De corpore [1655] y De homine [1658]), se proponen demostrar que la ley natural constituye la imprescindible norma moral, como regla del bien y del mal, de la constitución del Estado y de la estabilidad y paz sociales ${ }^{14}$. Según Locke la ley natural no sólo posee una precedencia temporal sobre la ley positiva, sino que, sobre todo, goza de una superioridad o precedencia en dignidad, de la que se deriva la inderogable necesidad de que la ley positiva se inspire y sea interpretada según las exigencias de la ley natural. En esta inferioridad y obligada fundación de la ley civil sobre la ley natural cifra Locke, en definitiva, las bases del orden político y de la paz social. He aquí, pues, la idea central de los Ensayos sobre la ley natural.

\section{Existencia y esencia de la ley natural}

Los Ensayos sobre la ley natural se inician con la cuestión general relativa a la existencia de la ley natural. El título de esta primera sección dice así: «Si existe una regla de conducta moral o ley natural: se afirma» (An detur morum regula sive lex naturae? Affirmatur). El estilo escolástico salta a la vista. Planteada la cuestión sobre el an sit (o sea, sobre la existencia) de la ley natural, responde Locke afirmativamente con una serie de cinco

una versión española, cf. J. Locke, La ley de naturaleza (ed. C. Mellizo), Tecnos, Madrid 2007, he preferido seguir la edición crítica de von Leyden, de la cual traduciré directamente del latín los textos oportunos.

12 La historia de la Lovelace Collection es la siguiente. A la muerte de Locke, la mitad de su biblioteca, así como la totalidad de sus trabajos y manuscritos fueron dados en legado a su pariente Peter King, Lord Chancellor de Inglaterra, hijo de su prima Anne King, nacida Locke. El legado permaneció en poder de la familia King hasta 1942, fecha en que el último propietario de la colección, el conde de Lovelace, depositó la mayor parte de los manuscritos, aún inéditos, y entre ellos los Essays on the Law of Nature, en la Bodleian Library de Oxford.

13 Las cuestiones que integran la obra son las siguientes: I. An detur morum regula sive lex naturae? Affirmatur; II. An Lex Naturae sit Lumine Naturae cognoscibilis? Affirmatur; III. An Lex Naturae Hominum Animis inscribatur? Negatur; IV. An Ratio per Res a Sensibus haustas pervenire potest in Cognitionem Legis Naturae? Affirmatur; V. An Lex Naturae cognosci potest ex Hominum Consensu? Negatur; VI. An Lex Naturae Homines obligat? Affirmatur; VII. An Obligatio Legis Naturae sit Perpetua et Universalis? Affirmatur; VIII. An Privata cujusque Utilitas sit Fundamentum Legis Naturae? Negatur.

14 Esta opinión es justamente la contraria de la sostenida por Hobbes, para quien en el estado de naturaleza no existe justicia, sino únicamente en el estado civil bajo la potestad de la ley y del legislador positivo. En lo relativo al estado de naturaleza, cf. T. HobBes, Leviathan, en «The English works of Thomas Hobbes of Malmesbury» (ed. W. Molesworth), vol. III, John Bohn, London 1839, cap. 13: «To this war of every man against every man, this also is consequent; that nothing can be unjust. The notions of right and wrong, justice and injustice have there no place. Where there is no common power, there is no law: where no law, no injustice». En lo que respecta al estado político, cf. TH. HoвBEs, Leviathan, cap. 26: «As also, that laws are the rules of just, and unjust; nothing being reputed unjust, that is not contrary to some law». Ambas traducciones son propias. 
argumentos. Pero, antes de exponer los argumentos sobre la existencia de la ley natural, es interesante hacer notar que Locke se cree en la necesidad de presentar una demostración, aunque sea breve, de la existencia de Dios. La demostración presentada se atiene al estilo de la llamada teología física (Physico-Theology), tan característica del pensamiento inglés del siglo XVII ${ }^{15}$. Locke siempre procede con orden. Así, dado que la ley natural es una ley de origen divino, primero hay que detenerse en la existencia del legislador, para pasar después a estudiar lo relativo a dicha ley, tanto en su existencia como en su esencia.

Pasando ya a considerar la existencia de la ley natural, Locke presenta cinco argumentos en favor de ésta, que podemos llamar así: el argumento del deber y la razón, el argumento de la conciencia de los hombres, el argumento del orden del mundo y regla de toda actividad, el argumento de la existencia de la sociedad y, finalmente, el argumento del reconocimiento social de la distinción entre virtud y vicio.

En primer lugar, retomando el razonamiento de Aristóteles, reconoce Locke que «el deber consiste en obrar conforme a la razón, en la medida que el hombre debe necesariamente realizar lo que la razón impone» ${ }^{16}$. Ahora bien, lo que la razón impone y la ley natural son una y la misma cosa. Aunque, como admite Locke, no todos los hombres vivan de acuerdo con esta ley, «en esta materia no debe darse crédito a la mayor parte de los hombres, sino a la parte más sana y razonable» ${ }^{17}$.

El segundo argumento sobre la existencia de la ley natural se deriva de la conciencia de los hombres. Es un hecho, dice Locke, que los hombres en lo íntimo de su conciencia no se absuelven del mal que han cometido. Ahora bien, si, de un lado, el juicio que cada uno formula sobre sí mismo es un testimonio de la existencia de la ley natural, por otro lado es claro que sin una ley no puede ser emitido juicio alguno; y esta ley no es una ley escrita, sino innata ${ }^{18}$.

15 La expresión Physico-Theology aparece por primera vez en la obra titulada Physico-Theology, or a Demonstration of the Being and Attributes of God, from his Works of Creation, publicada en 1713 por William Derham, inspirándose en el estilo de la apologética mecanicista, instaurado unos años antes por Robert Boyle e Isaac Newton para demostrar la existencia de Dios a partir de argumentos tomados de la nueva filosofía experimental y de la física mecánica. El estilo físico-teológico del razonamiento de Locke al inicio de la primera cuestión resulta evidente: «Dado que la presencia de Dios se nos muestra con evidencia por todas partes y se impone, por decir así, a la vista de los hombres ante la regularidad del curso de la naturaleza, como en otro tiempo aparecía evidente a causa de la frecuencia de los testimonios de los milagros, creo que no se hallará nadie dispuesto a sostener la inexistencia de Dios [...] Por tanto, una vez que se ha establecido el hecho (dudar del cual sería ilícito) de que un ser divino gobierna el mundo, en cuanto que ha ordenado al cielo moverse con un movimiento rotatorio ininterrumpido, a la tierra permanecer inmóvil, y a las estrellas brillar, ha impuesto confines incluso al mar indomable [...] hay que preguntarse por qué sólo el hombre habría de ser la única criatura que ingresa en este mundo exenta de sumisión a ley alguna, libre de toda jurisdicción, sin sabiduría ni regla algunas, sin norma alguna directiva de su vida» (J. LoCKE, Essays on the law of nature [Eln], I, 108). Cf. R. BoyLE, The Cristian Virtuoso shewing that by being addicted to Experimental Philosophy, a Man is rather assisted than indisposed to be a good Christian, printed by Edw. Jones for John Taylor and John Wyat, London 1690.

16 J. LocKe, Eln, I, 112: «Primum argumentum desumi potest ex Aristotelis testimonio ad Nicom., lib. 1, c. 7, ubi dicit quod ergon anthrópou esti psychés energeia kata lógon: [...] recte concludit officium hominis esse actionem secundum rationem adeo ut ea homini necessario agenda sunt quae dictat ratio». Cf. ARISTótelEs, Etica a Nicómaco, I, 1, 7.

17 J. LocKe, Eln, I, 114: «Hac igitur in re non major pars hominum sed sanior et perspicacior consulenda est».

18 Cf. J. LocKE, Eln, I, 116: «Secundum argumentum quo probatur dari legem naturae desumi potest ab hominum conscientiis, quod scilicet se judice nemo nocens absolvitur. Judicium enim illud quod de se quisque fert testatur dari legem naturae. Si enim non detur lex naturae cui nos nosmet morigeros praestare debere dictat ratio, 
El tercer argumento es tomado de la constitución de este mundo, pues así como todas las cosas observan en su modo propio de obrar una ley establecida y un modo de ser conforme a su propia naturaleza, así también el hombre no puede, en contraste con toda la creación, encontrarse libre de la observancia de alguna ley. Como afirma Tomás de Aquino, a quien cita Locke (por medio de una paráfrasis tomada de R. Hooker), «todo cuanto acontece en las cosas creadas es materia de la ley eterna» ${ }^{19}$. Por tanto, al hombre se le prescribe un modo de obrar conforme a su naturaleza, que es la de un ser racional y libre. Ahora bien, tales prescripciones no son otra cosa que la ley natural.

El cuarto argumento deriva del hecho mismo de la existencia de la sociedad humana, en cuanto que sin la ley natural los hombres no podrían vivir en sociedad y, por tanto, ésta no subsistiría. Dos son los elementos sobre los que la sociedad se funda: la forma del Estado (y del gobierno) y el respeto de los pactos. Pero, a su vez, estos elementos que garantizan la subsistencia de la sociedad se fundan en última instancia sobre la ley natural, sin la cual, por tanto, la sociedad no podría subsistir por mucho tiempo. «Eliminados estos fundamentos, la comunidad política está destinada a su ruina, del mismo modo que caen estos mismos fundamentos si se elimina la ley natural» ${ }^{20}$. Se trata de un poderoso argumento que, en lo esencial, procede lógicamente del siguiente modo. El Estado se sustenta, en última instancia, sobre la ley natural, a la cual se debe subordinar siempre la ley positiva. Las razones de este principio jurídico son tres: el deber de mantener la fe en los pactos concluidos, las obligaciones del Estado frente a los súbditos y las obligaciones de estos frente a aquél. Veámoslas. En primer lugar, dado que sólo la ley natural es motivo sólido del cumplimiento fiel de los pactos, si ésta no fuera respetada, terminaría haciéndose imposible tanto la constitución misma de la sociedad civil (ya que ésta procede del primero de los pactos, a saber del pacto de constitución de la sociedad) como la formación y duración de los gobiernos (que depende del segundo pacto fundamental, pacto de transmisión de la potestad). Pero, además de ésta, la ley natural cumple, según Locke, otras dos funciones no menos importantes, relativas a las obligaciones de la autoridad política y de los súbditos. Por eso, en segundo lugar, frente a toda pretensión abusiva del legislador y a las veleidades de un gobierno despótico que pretendiera arrogarse potestades que exceden su competencia ejecutiva, la ley natural se yergue como la salvaguardia fundamental de los derechos naturales de los ciudadanos, para cuya custodia ha sido constituida la misma sociedad política. En tercer lugar, finalmente, y

quomodo evenit quod eorum conscientia qui nullius alterius legis quibus aut diriguntur aut obligantur agnoscunt decreta de sua quidem vita et moribus fert sententiam et vel absolvit vel crimine alligat? cum sine lege aliqua nulla ferri potest sententia; quae lex non scripta est, sed innata».

19 J. LocKE, Eln, I, 116: «Tertium deducitur argumentum ab ipsa constitutione hujus mundi in quo reliqua omnia certam operationum suarum legem modumque naturae suae convenientem observant; id enim quod cuique rei formam et modum et mensuram agendi praescribit id demum lex est; id omne, quod in rebus creatis fit, materia est legis aeternae, inquit Aquinas». Cf. T. DE AQuino, STh, I-II ${ }^{\text {ae }}$, q. 93, a. 4. La paráfrasis de santo Tomás está tomada de R. Hooker, The Works of that Learned and Judicious Divine, Mr. Richard Hooker, in Eight Books of the Laws of Ecclesiastical Polity, At the Oxford Clarendon Press, Oxford 1876, I, 3, 1.

20 J. LocKe, Eln, I, 118: «Quartum argumentum desumitur ab hominum societate, cum sine hac lege hominibus inter ipsos nulla consuetudo aut conjunctio esse potest; duo enim sunt quibus niti videtur hominum societas, certa scilicet reipublicae forma ac regiminis constitutio, et pacti fides; quibus sublatis corruit omnis inter homines communitas, uti sublata hac lege naturae corruunt haec ipsa». 
por lo que respecta a los súbditos, sólo la ley natural garantiza debidamente tanto el respeto como el sometimiento a las leyes en conciencia y no por mera coerción exterior.

Finalmente, en quinto lugar, considera Locke la última razón a favor de la existencia de la ley natural, basada en el reconocimiento social de la distinción entre virtud y vicio y entre conducta decorosa y delictiva. Puesto que no hay delito donde no hay culpa, y no hay culpa donde no hay ley (nulla culpa, nullus reatus, ubi nulla lex), estos principios jurídicos presuponen la existencia de una ley en conformidad con la cual se enjuician tales conductas. Pero si no existiera la ley natural, la voluntad humana sería el único juez de sus acciones; y puesto que en tales condiciones el deber no sería exigible a nadie, es evidente que en tal estado el hombre, libre de todo vínculo, no haría otra cosa que entregarse a lo que le aconseja la utilidad, le dicta el placer o incluso le impone la fuerza de un impulso ciego. Por tanto, si no existiera la ley natural, no existiría la justicia ni la honestidad, ni razón alguna para prohibir cualquier conducta. El hombre sería el árbitro único y supremo de las propias acciones. Pero si esto no ocurre, ello se debe únicamente a que existe tal cosa como la ley natural. Esta ley, que prescribe hacer el bien y evitar el mal, «es eterna e inmutable y su valor no puede ser determinado ni por las leyes públicas de los hombres ni por la opinión privada» ${ }^{21}$.

Demostrada la existencia de la ley natural, pasa Locke a la cuestión del quid sit, es decir al análisis de su esencia. Pero como la esencia se expresa en el nombre, resulta oportuno recordar algunos de los nombres clásicamente atribuidos a la ley natural. Tres son los nombres que indican la misma ley natural, aunque considerada desde distintos puntos de vista: recta razón, si se considera la ley natural desde el punto de vista del hábito de los primeros principios morales, y así coincide con la sindéresis; luz natural, si se considera la ley desde el punto de vista del medio de su conocimiento, que es la razón práctica, es decir la razón aplicada a lo que debe ser hecho o evitado; y bien honesto o moral, considerada a la luz de los bienes que su cumplimiento asegura al hombre.

A la definición nominal sigue la definición real, que es la que aquí interesa. A este respecto, la esencia de la ley natural es presentada como, dice Locke, «la disposición de la voluntad divina, cognoscible por medio de la luz natural de la razón, que indica lo que es conforme o disconforme con la naturaleza racional, y por ello mismo se expresa con la formulación de un mandato o de una prohibición» ${ }^{22}$. Se trata de una afirmación fundamental, en estrecha correspondencia con cuanto se ha dicho sobre la noción suareciana de ley. Encontramos en esta definición un aspecto fundamental del pensamiento de Locke, que es el característico voluntarismo moderno en la definición de ley. En consecuencia, se declara Locke en desacuerdo con la definición de ley que pone como esencia de ésta una actividad ordenadora de la razón. Dice así: «Con menos precisión me parece que definen algunos [la ley] como un dictado de la razón [dictatum rationis] [...] porque en tal modo quedaría dis-

21 J. LockE, Eln, I, 120: «[...] quamcunque nempe honestatem aut turpitudinem habent virtutes et vitia eam omnem legi huic naturae debent, cum earum natura aeterna sit et certa, nec decretis hominum publicis nec privata aliqua opinione aestimanda».

22 J. LocKe, Eln, I, 110: «Haec igitur lex naturae ita describi potest quod sit ordinatio voluntatis divinae lumine naturae cognoscibilis, quid cum natura rationali conveniens vel disconveniens sit indicans eoque ipso jubens aut prohibens». 
minuida la dignidad del legislador supremo» ${ }^{23}$. Precisamente ésta era la opinión de Tomás de Aquino al afirmar que la esencia de la ley es una ordenación de la razón. Pero Locke cree que si se sigue esta opinión quedaría disminuida la dignidad del legislador supremo, porque, en realidad, dejaría de ser tal legislador supremo para convertirse en mero anunciador o maestro de la ley, sobreentendiéndose así que la ley le era de algún modo anterior o superior. Lo que aquí hay en juego no es de poca monta: es la relación entre entendimiento y voluntadlibertad, entre verdad y bien, una de las grandes cuestiones, por cierto, replanteadas por el voluntarismo tardomedieval. Por eso, finalmente, afirma Locke que, como toda ley tiene su razón formal (es decir, su esencia) en una «declaración de una voluntad superior», así la ley natural es verdadera ley, porque consiste en una prescripción que manda hacer u omitir algo, constituyendo a los hombres sometidos a ella en una verdadera obligación de obediencia ${ }^{24}$.

\section{El voluntarismo de Locke en la noción de ley natural}

Conviene que nos detengamos, aunque sea brevemente, a considerar la orientación voluntarista que se pone de manifiesto en la noción lockiana de ley. G. Bedeschi considera que no debe concederse gran importancia a la pretendida tendencia voluntarista de la concepción lockiana de la ley natural. Pero no da razones que apoyen esta opinión ${ }^{25}$. Desde luego, es claro que el cambio en la concepción de la naturaleza de la ley (de una concepción universalista-intelectual a otra de signo nominalista-voluntarista) al que se asiste entre los siglos XIV y XVII es indicio de un cambio profundo que se viene operando en la concepción del hombre, más centrada ahora en su particularidad, subjetividad y libertad. W. von Leyden, editor de los Ensayos sobre la ley natural, reconoce que hay razones de peso para sostener no sólo que Locke estaba al corriente de la obra jurídica de Suárez, particularmente del De Legibus, sino que, por diversos motivos, comparte la misma orientación de fondo que el filósofo granadino. El influjo de Suárez se constata -dice von Leyden- con particular evidencia en la determinación por parte de Locke de la voluntad divina como esencia o constitutivo formal de la ley natural. Por otro lado, siendo compartida la concepción voluntarista de la ley por la enseñanza de los reformadores protestantes, se explica mejor la amplia difusión que la misma encontró en los siglos XVI y XVII y que fuera adoptada por autores como Grotius, Spinoza, Pufendorf, así como por autores ingleses como Sanderson y Culverwell.

En la noción lockiana de ley es evidente el énfasis puesto en la voluntad, tan característico, por otro lado, de la obra jurídico-política de Suárez. La esencia de la ley es, pues, es el mandato. En definitiva, tanto en Suárez como en Locke, la ley consta de tres elementos constitutivos: 1) un acto procedente de la voluntad del legislador, 2) que prescribe un mandato o una omisión; y 3) que constituye al súbdito en el estado de obligación.

23 J. LocKe, Eln, I, 110: «Minus recte enim mihi videtur a nonnullis dici dictatum rationis [...] nisi supremi legislatoris minuendo dignitatem».

24 Cf. J. Locke, Eln, I, 110-112: «Ex his facile patet in ea omnia reperiri quae ad legem requiruntur. Nam primo declaratio est superioris voluntatis, in quo consistere videtur legis ratio formalis; quo autem modo humano generi innotescat postea fortassis inquirendi locus erit. Secundo, quod legis est proprium, quid agendum sit vel omittendum praescribit. Tertio homines obligat, omnia enim quae ad obligationem requiruntur in se continet; quamvis enim eo modo quo leges positivae non promulgatur, sufficienter tamen hominibus innotescit (quod sufficit), cum possibile sit solo lumine naturae eam cognoscere».

25 Cf. G. BedEschi, Introduzione a J. Locke, Saggi sulla legge naturale, Laterza, Roma-Bari 1996, 17. 
Actualmente, pues, consta con suficiente seguridad que la doctrina de Locke sobre la esencia de la ley (tanto natural como positiva) guarda una especial relación con Suárez, de quien ha sido tomada sea directa, sea indirectamente. En el plano del influjo directo sobre Locke, von Leyden da por segura esta relación, si bien advierte del peligro de exagerarla, minimizando así el efecto que otros escolásticos tardíos han podido ejercer sobre el filósofo inglés ${ }^{26}$. En el plano de una relación indirecta, que no excluye la anterior, dos autores adquieren una especial relevancia: Grotius y Culverwell. De ambos nos consta su profunda inspiración en la obra del teólogo y jurista español. De Grotius trataremos más adelante. Ahora digamos que la figura de Culverwell es en este sentido un caso claro de influjo indirecto de Suárez sobre Locke ${ }^{27}$. Al igual que Locke, Nathaniel Culverwell (1619-1651), un platónico de Cambridge, autor de An Elegant and Learned Discourse of the Light of Nature (1652), insistía en que la obligación que deriva de la ley no descansa en su interna racionalidad, sino que tiene que ser buscada sobre todo en una voluntad suprema. Aunque Culverwell y Locke admiten que la ley presupone un acto del intelecto, y que por tanto hay un orden eterno de las cosas, insisten en que el constitutivo formal de la ley descansa en la voluntad del legislador, no en su entendimiento. En breve, al igual que Suárez, tanto Culverwell como Locke aceptan que las obligaciones morales que surgen de la ley proceden, en última instancia, del mandato de la voluntad divina ${ }^{28}$.

En realidad, el voluntarismo jurídico está presente en un buen número, si no en la mayoría de las teorías modernas de la ley. También Hugo Grotius, por ejemplo, en su De iure belli ac pacis ${ }^{29}$, de quien se conoce bien su deuda intelectual con Suárez ${ }^{30}$, se hace eco de

26 Cf. W. VON LEYDEN, Introduction a J. Locke, Essays on the Law of nature, 36-37: «As regards Suarez, there is reason to believe that Locke was acquainted with his Tractatus de Legibus ac Deo Legislatore, which provides a comprehensive and at the same time detailed exposition of medieval doctrines of natural law. [...] To say, however, that any of the scholastic notions in the Essays were derived by Locke from Suarez is to minimize the effect that other thinkers who borrowed from the late Scholastics had on him».

27 Robert A. Greene, en su estudio introductorio de la obra de Culverwell (N. Culverwell, An Elegant and Learned Discourse of the Light of Nature, ed. R.A. Greene-H. MacCallum, University of Toronto Press, Toronto 1971), afirma en un sentido general que "el Discourse of the Light of Nature es esencialmente una flor protestante en el árbol de la escolástica, cuya posición filosófica y espíritu se derivan de Suárez y Tomás de Aquino" (xv). Más adelante, a propósito de la esencia de ley natural en Culverwell, afirma Greene: "Las páginas finales del capítulo sexto se inspiran casi por completo en las consideraciones de Suárez sobre la cuestión de la precedencia del entendimiento divino o de la voluntad en la constitución de la ley" (xvi). Además de las frecuentes citas de Suárez, concluyendo el capítulo sexto Culverwell hace suya la noción de ley de Suárez, diciendo: "but now before all this can rise up to the height and perfection of a Law: there must come a Command from some Superiour Powers, from whence will spring a Moral obligation also, and make up the formality of a Law"(55), inspirándose en el texto del De Legibus, 2, 5, 6, que cita.

28 Cf. W. von LEYden, Introduction a J. Locke, Essays on the Law of nature, Oxford, Clarendon Press 1954,40

29 Cf. H. Grotius, De iure belli ac pacis libri tres, in quibus jus naturae et gentium, item juris publici praecipua explicantur, Apud Nicolaum Buon, Paris 1625.

30 Por confesión del propio Grotius sabemos que estaba familiarizado con las obras de Suárez. Como afirma en la Carta CLIV, a Juan Cordesius, Suárez es un filósofo y teólogo de penetración tan grande, que apenas hay quien se le iguale. Además de las cuatro veces que directamente se cita el Tractatus de legibus en su De iure belli ac pacis (I, 4, §15; II, 4, §5; II, 14, §5; II, 23, §13), la influencia de Suárez sobre Grotius es mucho mayor de lo que se deduce de las referencias directas a su pensamiento. Por razones de prudencia Grotius debía ocultar o silenciar en su tratado la autoridad de Suárez, cuya doctrina sobre el tiranicidio ofendía al rey de Francia, de cuya hospitalidad disfrutaba Grotius mientras redactaba el libro. La Defensio fidei de Suárez había sido quemada por orden del Parlamento de París. Como han indicado J. Kosters y T. A. Walkers, el sistema de derecho internacio- 
una concepción semejante de ley natural. Según Grotius la ley natural se caracteriza por ser aquella ley que procede, además de la naturaleza humana (en especial de la sociabilidad y razón humanas), «de la libre voluntad de Dios» ${ }^{31}$. Una vez más, el acento sobre el elemento volitivo de la actividad legislativa denota inequívocamente la tendencia voluntarista de esta descripción de ley natural. Es precisamente esto lo que acabamos de ver en la definición de ley natural de Locke.

Un aspecto a resaltar de la esencia de la ley (natural) se encuentra en la sección $7^{a}$ de los Ensayos sobre la ley natural. Estudiando la obligatoriedad de la ley natural, Locke indaga un nuevo fundamento de la ley natural, de modo semejante a como acabamos de ver en Grotius ${ }^{32}$, que repercutirá sobre la concepción de su esencia. La nueva perspectiva adoptada en esta sección permite a Locke corregir, en parte, la orientación voluntarista, que ve únicamente en la voluntad divina la fuente de la moralidad. Se esfuerza así nuestro autor en buscar una explicación complementaria de la obligatoriedad de la ley natural, que podemos entender como una atenuación de la definición de ley antes propuesta. Inspirándose en Grotius, que admite una doble procedencia de la ley natural (la naturaleza humana, primero y la libre voluntad de Dios, después), también Locke considera posible un acceso inicial a la ley natural por medio del estudio de la naturaleza humana. Como algunos autores han hecho ver, se trata de indagar la posibilidad de una fundación inicial, puramente racional, de la ley natural y de la ética. Se considerará entonces que las normas morales son válidas con independencia de cualquier mandato o voluntad externos (incluso divinos), porque el hombre, por medio de la razón, descubre que las normas morales tienen su origen y su justificación próximas en la naturaleza humana. Así, considerando que las normas morales no pueden ser más que como son, de acuerdo a su relación con la naturaleza humana, Locke llega a ver en ésta el fundamento de la ley natural, que es conocida por la razón humana, que, a su vez, se convierte ahora en fuente autónoma de la obligación ${ }^{33}$. Ahora bien, es claro que de este modo Locke se acerca al argumento ex hypothesi de Grotius sobre la validez de la ley natural etiamsi daremus non esse Deum ("aunque aceptáramos que no existe Dios") popularizado con la fórmula etsi Deus non daretur.

nal propuesto por Grotius es esencialmente idéntico al expuesto por Suárez. Cf. J. Kosters, Les fondaments du droit des gens, en «Biblioteca Isseriana», IV, Leyden 1925 y T. A. WALKERs, A history of the Law of Nations, Cambridge 1899. Conviene mencionar finalmente la hoja suelta del manuscrito De iure predae de Grotius, descubierto en 1864, que titulada Nova declaratio, es un resumen de la famosa doctrina doctrina suareciana de las tres ramas del Derecho: natural, civil y de gentes. Kosters, que fue quien dio a conocer este texto, llegó a la conclusión en 1925 de que Grotius recorría la misma senda abierta por Suárez. Al respecto, cf. J. Kosters, Les fondaments du droit des gens, 47. E. Nys, J. Brown Scout y C. Barcia Trelles han llegado a conclusiones semejantes. Cf. E. Nys, «Les jurisconsults espagnols et la science du droit des gens»: Revue de droit international et de législation comparée 14 [1922] 360-387; J. BRown Scout, El origen español del Derecho internacional moderno, Valladolid 1928; C. BARCIA Trelles, Internacionalistas españoles del siglo XVI: Francisco Suárez (1546-1617), Universidad de Valldolid, Valladolid 1934.

31 H. Grotius, De iure belli ac pacis, Prolegomena, §12: «proveniente de la libre voluntad de Dios» (veniens scilicet ex libera Dei voluntate).

32 Cf. J. LocKe, Eln, VII, 190: «An obligatio legis naturae sit perpetua et universalis? Affirmatur».

33 Cf. W. von LEYdEN, Introduction a J. Locke, Essays on the Law of nature, 51. 


\section{Excursus: Grotius, Suárez y la validez de la ley natural según la fórmula etiamsi daremus non esse Deus}

En los Prolegomena del De iure belli ac pacis, después de indagar la esencia de la ley natural, se pregunta Grotius cuál es el fundamento de la obligatoriedad de esta ley. La cuestión, brevemente expuesta, se resume en la alternativa de si la ley natural vincula a los hombres porque es de procedencia divina o porque, arraigando en la naturaleza humana, es un contenido normativo autónomo descubierto por la razón. La solución, bien planteada la cuestión, es que la ley natural obliga por proceder en última instancia de Dios, identificándose con la ley eterna; pero igualmente puede decirse, y es más lógico empezar por aquí, que como fundamento próximo, la ley natural obliga en razón de las mismas exigencias de la naturaleza humana, de la cual-como dice Grotius-fluyen los principios internos del obrar humano. Desde esta perspectiva conviene interpretar los números 11 y 12 de los Prolegomena del De iure belli ac pacis. Afirma el número 11: «Ciertamente estas cosas que hemos dicho [todo lo relativo a la ley natural] tendrían validez aunque concediésemos -lo que no se puede hacer sin sumo delito- que no hay Dios o que no se cuida de las cosas humanas» ${ }^{34}$. Y más adelante, prosigue en el número 12:

Y ésta es ya otra fuente del derecho, más allá de la naturaleza, el cual proviene sin duda de la libre voluntad de Dios, respecto de la cual nuestro mismo entendimiento nos dicta irrefragablemente que le debemos estar sujetos. Pero, aún el mismo derecho natural de que hemos tratado [...], aunque fluya de los principios internos del hombre, con todo puede en justicia atribuirse a Dios, porque él mismo quiso que existieran en nosotros tales principios ${ }^{35}$.

El sentido, pues, de estas expresiones de Grotius es claro. La causa próxima de la obligatoriedad para todos los hombres de ley natural es su radicación en la naturaleza humana y su conocimiento por la luz natural de la razón. Pero ello no es obstáculo para que, en última instancia, se deba afirmar que su fundamento absoluto se halla en la voluntad divina, presupuesta su esencia y su sabiduría. En este sentido, la definición de ley natural, proporcionada por el propio Grotius más adelante, es una muestra de mesura en la comprensión del fundamento de la misma: «El derecho natural es el dictado de la recta razón, que indica que alguna acción, por su conformidad o disconformidad con la misma naturaleza racional, tiene fealdad o necesidad moral, y por consiguiente está prohibida o mandada por Dios, autor de la naturaleza» ${ }^{36}$.

34 H. Grotius, De iure belli ac pacis, Prolegomena, §11: «Et haec quidem quae iam diximus, locum [aliquem] haberent etiamsi daremus, quod sine summo scelere dari nequit, non esse Deum, aut non curari ab eo negotia humana)».

35 H. Grotius, De iure belli ac pacis, Prolegomena, §12: «Et haec iam alia iuris origo est praeter illam naturalem, veniens scilicet ex libera Dei voluntate, cui nos subiici debere intellectus ipse nopster irrefragabiliter dictat. Sed et illud ipsum de quo egimus naturale ius [...] quamquam ex principiis homini internis profluit, Deo tamen asscribi merito potest, quia ut talia principia in nobis existerent ipse voluit».

36 H. Grotius, De iure belli ac pacis, I, 1, 10, 1: «Jus naturale est dictatum rectae rationis, indicans actui alicui, ex ejus convenientia aut disconvenientia cum ipsa natura rationali ac sociali, inesse moralem turpitudinem, aut necessitatem moralem, ac consequenter ab auctore naturae Deo talem actum aut vetari, aut praecipi». 
Lo mandado por Dios, autor de la naturaleza humana, por medio de la ley natural está en profunda armonía con lo que percibe la recta razón, la cual, considerando la adecuación o no de un acto con las exigencias de la naturaleza humana, lo declara como prescrito o prohibido por el mismo Dios. Por tanto, es un falso dilema plantear en términos de exclusividad dónde se halla el fundamento de la ley natural. En realidad, el fundamento es doble, con una intrínseca relación de participación del fundamento inmediato (la naturaleza humana) en el fundamento último (la ciencia y voluntad divinas como ley eterna) ${ }^{37}$. De tal modo la ley natural es expresión para la criatura del fundamento último (la ley eterna), que descansa en la esencia divina, que -como dice Grotius- ni siquiera Dios puede cambiar su inmutable contenido $^{38}$. Por tanto, la fórmula de Grotius «etiamsi daremus -quod sine summo scelere dari nequit- non esse Deum» (diferente, como puede verse, de la que suele atribuírsele: «etsi Deus non daretur», sobre todo por el añadido referente al delito implícito en tal suposición) no tiene por fin poner en duda la existencia de Dios, ni sugerir la independencia de la vida social de toda perspectiva teológica. Su propósito, es más bien, como acabamos de mostrar, poner de manifiesto la consistencia ontológica y relativa autonomía de la naturaleza humana como fuente inmediata de la que fluyen los principios de la ley natural.

Por otro lado, como han observado distintos autores ${ }^{39}$, la fórmula de Grotius tiene una larga historia en la tradición jurídica. Parece haberle sido sugerida por Suárez, quien en un pasaje del De Legibus expone la opinión -rechazada por el teólogo granadino- de Gregorio de Rímini sobre el carácter declarativo, no preceptivo, de la ley natural. Según Gregorio de Rímini la ley natural sería válida «aunque Dios no existiera o aunque no hiciera uso de la razón o aunque Él no juzgara de las cosas correctamente» («licet Deus non esset vel non uteretur ratione vel non recte de rebus iudicaret» $)^{40}$.

Una vez admitido el doble fundamento de la ley natural (naturaleza humana y ley eterna), queda por determinar si, en razón de su fundamento último, la ley natural es una indicación o una prescripción. Se trata de un aspecto relacionado con lo anteriormente visto sobre la concepción voluntarista de la ley. Suárez dedica a esta temática el capítulo sexto del libro segundo de De Legibus, titulado «Si la ley natural es realmente una ley divina preceptiva». Se pregunta Suárez «si puede afirmarse que la ley natural ha sido dada por Dios como legislador ${ }^{41}$. Admite el teólogo granadino abiertamente que, desde el punto de vista de la causa eficiente, «la ley natural y sus dictámenes son un don divino que procede del Padre de las luces». Pero la cuestión no es si la ley natural procede de Dios como causa eficiente, cosa obvia, sino si, en cuanto ley, procede de Dios como causa formal, es decir, si procede

37 Cf. M. Jiménez de PARga, «Hugo Grotius y el proceso de constitución de la realidad jurídica moderna»: Revista de estudios políticos 74 (1954) 119-143, 139: «Grotius se apoya en una esencial concepción teística del mundo, porque si bien es cierto que la fuente próxima del derecho — en De iure belli- es la naturaleza humana, su fuente primera será siempre Dios, autor y artífice de esa naturaleza. El derecho, por tanto, no es producto de la razón humana autónoma».

38 Cf. H. Grotius, De iure belli ac pacis, I, 1, 10, 5: «Est autem ius naturale adeo immutabile, ut ne a Deo quidem mutari queat».

39 Cf. G. Del Vecchio, Lezioni di filosofia del diritto, A. Giuffrè, Milano 1950, 54. Cf. también G. Fassó, «Ugo Grozio tra Medioevo ed Età moderna»: Rivista di filosofia 41 (1950) 179-189; M. JimÉnEZ DE PARGA, «Hugo Grotius y el proceso de constitución de la realidad jurídica moderna», 138.

40 F. SuÁrez, De legibus, II, 6, 3.

41 F. SuÁrez, De legibus, II, 6, 2. 
de Dios «como legislador que [con su libre voluntad] manda y obliga», porque del hecho de que «Dios sea la causa eficiente y como el maestro de la ley natural [...] no se sigue que Dios sea su legislador» ${ }^{42}$. En definitiva, según Suárez, dar a conocer una ley no es imponerla, siendo así que lo propio del legislador es imponer con su voluntad mandatos y prohibiciones. De nuevo, como vemos, aparece aquí el concepto voluntarista de ley.

Admite Suárez que hay «una opinión que sostiene que la ley natural no es una ley preceptiva [...], sino sólo indicativa de lo que ha de hacerse o evitarse, de lo que por su propia naturaleza es bueno y necesario o intrínsecamente malo» ${ }^{43}$. Siguiendo este criterio, muchos distinguen dos clases de ley: una indicativa y otra preceptiva, afirmando que la ley natural es ley en el primer sentido y no en el segundo. Tal es la opinión de Gregorio de Rímini, que hace suya la tesis de Hugo de San Víctor. Gregorio de Rímini argumenta a favor de la tesis de la naturaleza declarativa de la ley natural, diciendo que el pecado es obrar contra la recta razón más que contra la razón divina; de manera que, «si por un imposible, la razón divina o el mismo Dios no existiera [...], y en tales circunstancias alguien obrara contra la recta razón (angélica o humana u otra cualquiera, si la hubiera), pecaría». La razón de ello es que «si se juzga con propiedad, el pecado no es una acción contra la razón divina, sino contra la recta razón de algo». Así, continúa Gregorio de Rímini, «no es pecado una acción porque va contra la razón divina en cuanto es divina, sino en cuanto es recta» ${ }^{44}$.

Siguen esta misma opinión Gabriel Biel ${ }^{45}$, Jacques Almain y Antonio de Córdoba. Según todos ellos la ley natural, como quiera que no depende de la voluntad divina, no procede de Dios en cuanto legislador y, por tanto, Dios no se comporta por medio de ella como un superior que ordena o prohíbe. Aquí es donde Suárez propone la fórmula después popularizada por Grotius:

42 F. SuÁREZ, De legibus, II, 6, 2.

43 F. SuÁrez, De legibus, II, 6, 3.

44 G. DE RímINI, In librum secundum Sententiarum, Venetiis 1522, dist. 34, q. 1, a. 2: «Quidquid est contra rectam rationem, est contra aeternam legem. Ac per hoc secundum Augustinum recte dicitur peccatum esse factum vel dictum vel concupitum aliquid contra recta rationem, id est, ut post patebit, facere vel dicere vel concupiscere (quae omnia sub vocabulo agendi comprehenduntur) contra rectam rationem. Si quaeratur cur potius dico absolute contra rectam rationem quam contractae contra rationem divinam, respondeo ne putetur peccatum esse praecise contra rationem divinam, et non contra quamlibet rectam rationem de eodem; aut aestimetur aliquid esse peccatum, non quia est contra rationem divinam inquantum est recta, sed quia est contra eam inquantum est divina. Nam si per impossibile ratio divina sive Deus ipse non esset, aut ratio illa esset errans, adhuc, si quis ageret contra rectam rationem angelicam vel humanam aut aliquam si qua esset, peccaret». Las cursivas son mías.

45 Cf. G. BIEL, Commentarius in Secundum librum Sententiarum [...], apud Thomam Bozolam, Brixiae 1574, dist. 35, quaestio unica. Ya en el Index libri secundi dice Biel: «Distinctio XXV: quaestio unica: [...] Quid peccatum et de eius definitionibus [...] Quommodo se habet lex aeterna ad recta rationem. Lex indicativa est, quae tantum indicat quid bonum aut malum. Et lex imperativa, quae praecipit vel prohibet formaliter et expresse». Más adelante, ya en el cuerpo de la distinción XXXV expone el siguiente razonamiento Biel: «Unde potest ex illis elici illa definitio brevis peccati. Peccatum actuale est voluntaria commissio vel omissio contra recta rationem [...] Dicitur autem contra recta rationem et non contra divinam rationem, ne putetur peccatum esse praecisse contra rationem divinam et non contra quamlibet rationem recta de eodem. Aut ne aestimetur aliquid esse peccatum, non quia est contra rationem divinam inquantum recta, sed quia est contra eam inquantum est divina. Nam $s i$ per impossibile Deus non esset, qui est ratio divina, aut ratio divina esset errans, adhuc si quis ageret contra recta rationem angelicam, vel humanam aut aliam aliquam, si qua esset, peccaret». Las cursivas son mías. Como puede comprobarse, las coincidencias de este texto con el de la nota anterior, de Gregorio de Rímini, son tales que nos obligan a pensar en una recepción a veces casi literal. 
Gregorio de Rímini, a quien siguen los demás, dice incluso que, aunque Dios no existiera (licet Deus non esset) o aunque no hiciera uso de la razón o aunque Él no juzgara de las cosas rectamente, con tal de que en el hombre se diera ese mismo dictamen de la recta razón -estableciendo, por ejemplo, que es malo mentir-, dicho dictamen tendría el mismo carácter de ley que hoy tiene, ya que sería una ley manifestativa de la malicia que existe intrínsecamente en el sujeto ${ }^{46}$.

La segunda opinión, diametralmente opuesta a la anterior, afirma que «la ley natural consiste únicamente en un mandato o prohibición divina que procede únicamente de la voluntad de Dios como autor y rector de la naturaleza ${ }^{47}$. Es la tesis de los nominalistas puros (Ockham, Gerson, Ailly), según los cuales «ningún acto es malo, si no en cuanto que Dios lo ha prohibido, pues no hay acto malo que no pueda hacerse bueno si Dios lo ordena y viceversa ${ }^{48}$. Según estos autores, la ley natural consiste en los preceptos divinos libremente dictados por Dios, quien los puede abolir o cambiar. Por tanto, en lo que se refiere a la ley natural, «toda la razón de bien y de mal radica en la voluntad de Dios y no en el juicio del entendimiento -incluido el del mismo Dios- ni en las propias cosas prohibidas o mandadas por esa ley» ${ }^{49}$.

Frente a estas dos opiniones, Suárez adopta una vía intermedia, según la cual «la ley natural no es sólo indicativa del mal y del bien, sino que implica también una verdadera prohibición del mal y un mandato del bien ${ }^{50}$. Si toda ley es un acto de la voluntad de un superior que obliga a un súbdito, y si la ley natural es verdadera ley, entonces ésta será un acto de un superior (Dios) que obliga a un súbdito (la criatura racional). Pero la ley natural es un acto de la voluntad divina, que es justa y recta, porque lleva implícitamente el orden de la justicia como es conocido por la sabiduría divina. Dios, que no puede contradecirse ni negarse a sí mismo, no puede abolir el orden de su propia justicia, tal como su ciencia le indica. De manera que Dios no puede dejar de prohibir lo que es malo y, por lo mismo, contrario a la razón natural. Como se ve, por medio de estas consideraciones Suárez introduce una atenuación o moderación en su concepción voluntarista de la ley.

\section{El fundamento de la obligatoriedad de la ley natural según Locke}

Las tres últimas secciones de los Ensayos sobre la ley natural de Locke están escritas en polémica con Hobbes. Nos ocupamos ahora de la sección sexta, titulada «Si la ley natural obliga a los hombres: se afirma» («An lex naturae homines obligat? Affirmatur»). En ella se analizan dos aspectos: desde una perspectiva negativa, al inicio de la cuestión, se rechaza la tesis de Hobbes, que identifica la obligatoriedad de la ley natural con el propio interés y provecho; más adelante, desde un punto de vista positivo, mediada ya la cuestión, se indaga el verdadero fundamento de la obligación que la ley natural impone a todos los hombres.

46 F. SuÁREZ, De legibus, II, 6, 3.

47 F. SuÁrez, De legibus, II, 6, 4.

48 F. SuÁrez, De legibus, II, 6, 4.

49 F. SuÁrez, De legibus, II, 6, 4.

50 F. SuÁrez, De legibus, II, 6, 5. Las cursivas son mías. 
Después de rechazar la posición de Hobbes, inicia Locke el estudio del fundamento de la obligatoriedad de la ley natural. Se propone, para ello, la siguiente noción de obligación, inspirada en Justiniano: «Obligación es el vínculo tutelado por el derecho [o por la ley], en razón del cual alguien está sometido al cumplimiento de algo debido» ${ }^{51}$. Descrita de este modo la obligación, hay que preguntarse de dónde trae origen el vínculo jurídico en el que ésta consiste. La respuesta es que su origen se halla en la situación de dominio y potestad que un superior tiene sobre alguien y sobre sus acciones. De manera que «estamos vinculados por una obligación en cuanto estamos sometidos a alguien ${ }^{52}$. En el caso de la ley natural, que tiene a Dios por autor, la situación de dominio y la consiguiente obligación de obediencia, es particularmente clara. Esta obligación deriva tanto de la sabiduría divina del legislador como del derecho que el creador tiene sobre su criatura. En definitiva, «en Dios se resuelve toda obligación, y nosotros estamos obligados a prestar obediencia al mandato de su voluntad» ${ }^{53}$. La obligación, por tanto, es precedida por un deber de obediencia a un poder superior, que es su verdadero fundamento, y que no es otro que el título de Dios como creador ${ }^{54}$.

Con todo, la obligación surge no tanto de la situación de subordinación frente a un poder superior, sino de la subordinación frente a la voluntad de dicho poder en cuanto manda algo. Tal es la esencia de la obligación: ser determinado por la voluntad de alguien, bajo cuya jurisdicción (o potestad) se está constituido ${ }^{55}$. Pero la ley (que es dada a un ser racional, dotado de conocimiento), debe, para su perfección, ser conocida por aquél a quien es dirigida. Hay que distinguir, por ello, dos sentidos en la ley: un sentido efectivo y otro terminativo (o perfectivo). El primer sentido se refiere a la elaboración de la ley, antes de ser conocida por el que está obligado a cumplirla. En este sentido la esencia de la ley se constituye por la voluntad del superior. El segundo sentido, en cambio, añade la toma de conocimiento de quien está sometido a ella. En tal sentido, la ley requiere para su perfección ser promulgada. Así pues, la obligación surge no sólo de una potestad superior, y tampoco de la sola voluntad de un poder superior, sino de la declaración de la voluntad de un poder superior. La ley no es otra cosa, en realidad, que aquella declaración de voluntad, dice Locke $^{56}$. Por tanto, Dios creador y legislador es causa de la obligación en cuanto potestad superior que vincula con su voluntad, suficientemente manifiesta o declarada. A estas alturas nos es ya suficientemente clara la concepción voluntarista de la ley en Locke.

51 J. LocKe, Eln, VI, 180: «Ut vero cognoscatur quomodo et quantum obligat lex naturae, pauca de obligatione praemittenda sunt, quam sic definiunt juris consulti, scilicet quod sit vinculum juris quo quis astringitur debitum persolvere, ubi per jus intelligunt legem civilem»; cf. IUsTINIANUs, Institutiones, III, XIII, 1: «Obligatio est iuris vinculum, quo necessitate adstringimur alicuius solvendae rei, secundum nostrae civitatis iura».

52 J. LOCKE, Eln, VI, 180: «in quantum alteri subjicimur in tantum obligationi obnoxii sumus».

53 J. LocKE, Eln, VI, 182: «in Deum enim ultimo resolvitur omnis obligatio, cujus voluntatis imperio nos morigeros praestare ideo tenemur».

54 Cf. J. LocKe, Eln, VI, 182: «quia, cum ab eo accepimus et esse et operari, ab ejus voluntate utrumque dependet, et eum modum quem ille praescribit observare debemus».

55 Cf. J. Locke, Eln, VI, 184: «prima causa omnis obligationis et a qua fluit formalis illius ratio, et id est voluntas superioris».

56 Cf. J. Locke, Eln, VI, 184: «quod nihil aliud est quam declaratio istius voluntatis, quam alio nomine legem vocamus». 
Ahora bien, la fuerza obligante de cualquier ley depende del grado de superioridad del legislador del que emana. Sólo la ley divina, de la cual la ley natural es una forma primordial, obliga absolutamente. Toda otra legislación trae su fuerza vinculante de ella. Por tanto, obligante de por sí, con fuerza propia, es sólo la voluntad divina, sea ésta promulgada por medio de la luz natural (y tal cosa es la ley natural), sea dada a conocer por medio de la revelación a determinadas personas (a las cuales únicamente obliga) por medio de «algunos hombres inspirados por Dios». En cambio, la fuerza obligante, procedente de un poder delegado es obviamente menor. Se trata en este caso de un poder indirecto, como el de los padres sobre los hijos o el del rey sobre sus súbditos; y en consecuencia, de una obligación indirecta, a la que, sin embargo, se está sometido por voluntad divina. Por tanto, «todos los demás legisladores han recibido el poder que ejercitan sobre los demás, el derecho de legislar y de imponer obediencia, sólo de Dios» ${ }^{57}$. De manera que «a tales legisladores se debe obediencia porque ésa es la voluntad y el mandato de Dios, de modo que prestando obediencia a ellos, se obedece a Dios ${ }^{58}$.

Por otro lado, como la ley natural (en cuanto voluntad de Dios, legislador omnipotente) es dada a conocer por medio de la luz natural de la razón, y ésta no falta a ningún hombre (pues no es hombre quien no la tiene), la ley natural obliga universalmente, es decir, a todos los hombres. Más aún, sólo la ley divina (natural o positiva) es directamente obligante, como ya se ha dicho. Pero de esto se siguen importantes consecuencias. Siendo la voluntad de la divinidad el fundamento último de toda obligación impuesta por cualquier ley, se sigue que «las leyes del magistrado derivan toda su fuerza del carácter obligante de la ley natural»59. Igualmente se sigue de dicho principio que si, por suponer un imposible, se aboliera la ley natural, «se destruiría al mismo tiempo todo ordenamiento político entre los hombres, toda autoridad, todo orden y convivencia social» ${ }^{60}$. Más aún. No se debe obedecer al rey tanto por temor (ex metu), porque siendo más fuerte puede obligarnos a ello (pues tal cosa significaría establecer sólidamente el poder de los ladrones, tiranos y piratas), sino por conciencia (ex conscientia), porque la autoridad del rey sobre nosotros proviene del mandato de la ley natural, en virtud del cual hay que someterse al que ha sido constituido en autoridad sobre el hombre ${ }^{61}$. En consecuencia, la obligación de obedecer a la ley civil procede de la ley natural. De ahí que no estemos constreñidos (cogimur) a su obediencia por el poder del magistrado, sino obligados (obligamur) a la misma por el derecho natural y por Dios mismo ${ }^{62}$.

$* * *$

En resumen, se puede afirmar sin temor a error que la orientación voluntarista de la filosofía jurídica de Locke presente en los Ensayos sobre la ley natural es típicamente moderna. El empleo de un léxico que enfatiza el elemento volitivo (poder, mandato, imperio,

57 J. LocKe, Eln, VI, 186: «totum illud imperium quod in alios obtinent et jus leges ferendi et ad obsequium obligandi a solo Deo mutuantur legislatores reliqui».

58 J. LocKe, Eln, VI, 186: «quibus ideo tenemur obedire quia Deus sic vellet sic jubet, adeo ut illis obtemperando Deo etiam paremus».

59 J. LocKE, Eln, VI, 188: «cum magistratus civilis leges vim suam omnem ex hujus legis obligatione mutuentur».

60 J. Locke, Eln, VI, 188: «adeo ut inter eos legem naturae si tollas omnem inter homines civitatem, imperium, ordinem, et societatem simul evertis».

61 Cf. J. LocKe, Eln, VI, 188.

62 Cf. J. LocKe, Eln, VI, 188. 
superior-súbdito, declaración de voluntad, etc.) como esencia de la ley, en detrimento de la aportación de la razón, tiene su origen en doctrinas antropológicas y jurídicas tardomedievales de orientación nominalista-voluntarista. En este contexto Suárez viene a ser el canal fundamental de transmisión a la modernidad del concepto de ley elaborado por Escoto, Ockham y sus respectivas escuelas. Sea directa o indirectamente, el influjo suareciano sobre el concepto de ley en Locke es cierto. También se debe a este influjo el estilo de pensamiento y de exposición que puede llamarse, con todo rigor, escolástico, tal como encontramos en los Ensayos sobre la ley natural de Locke. Finalmente, encontramos también en Suárez la cuestión del doble fundamento de la obligatoriedad de la ley natural (luego continuada por Grotius y Locke), sea en la naturaleza humana sea en la voluntad divina, no tanto como un intento de secularización de la noción de ley, de sociedad y de hombre, como se pretende frecuentemente, sino más bien con la intención de atenuar el exceso de un voluntarismo exagerado, que hace descansar la bondad o maldad de las acciones humanas únicamente en el mandato de la libérrima voluntad divina, por el sólo hecho de ser divina y no de ser justa, recta y buena.

\section{Referencias}

Aquino, T. De (1892), Summa theologiae, I-II ${ }^{\mathrm{ae}}$, en «S. Thomae Aquinatis, Doctoris Angelici, Opera omnia iussu impensaque Leonis XIII P. M. edita, t. VII» (ex Typographia Polyglotta Vaticana, Romae).

Barcia Trelles, C. (1934), Internacionalistas españoles del siglo XVI: Francisco Suárez (1546-1617), Universidad de Valladolid, Valladolid.

Bastit, M. (1990), Naissance de la loi moderne: la pensée de la loi de Saint Thomas a Suárez, PUF, Paris.

Bedeschi, G. (1996), Introduzione a J. Locke, Saggi sulla legge naturale, Laterza, RomaBari.

Biel, G. (1574), Commentarius in Secundum librum Sententiarum [...], apud Thomam Bozolam, Brixiae.

Boyle, R. (1690), The Cristian Virtuoso shewing that by being addicted to Experimental Philosophy, a Man is rather assisted than indisposed to be a good Christian, printed by Edw. Jones for John Taylor and John Wyat, London.

Brown Scout, J. (1928), El origen español del Derecho internacional moderno, Valladolid.

Culverwell, N. (1971), An Elegant and Learned Discourse of the Light of Nature, ed. R.A. Greene-H. MacCallum, University of Toronto Press, Toronto.

Fassó, G. (1950), «Ugo Grozio tra Medioevo ed Età moderna»: Rivista di filosofia 41, 179189.

Grotius, H. (1621), De iure belli ac pacis libri tres, in quibus jus naturae et gentium, item juris publici praecipua explicantur, Apud Nicolaum Buon, Paris.

Hobbes, T. (1839) Leviathan, en «The English works of Thomas Hobbes of Malmesbury» (ed. W. Molesworth), vol. III, John Bohn, London.

Hooker, R. (1876), The Works of that Learned and Judicious Divine, Mr. Richard Hooker, in Eight Books of the Laws of Ecclesiastical Polity, At the Oxford Clarendon Press, Oxford. 
Jiménez de Parga, M. (1954), «Hugo Grotius y el proceso de constitución de la realidad jurídica moderna»: Revista de estudios políticos 74, 119-143.

Kosters, J. (1925), Les fondaments du droit des gens, en «Biblioteca Isseriana», IV, Leyden. Leyden, W. von (2007), Introduction a J. Locke, Essays on the Law of nature.

Locke, J. (1824), The Works of John Locke in Nine Volumes (12 ${ }^{\mathrm{a}}$ ed.) Rivington, London.

Locke, J. (2007), Essays on the Law of Nature. The Latin Text with a Translation, Introduction and Notes (ed. W. von Leyden), at the Clarendon Press, Oxford 1954, repr. 2007.

Locke, J. (2007), La ley de naturaleza (ed. C. Mellizo), Tecnos, Madrid.

Prieto, L. (2013), Suárez y el destino de la metafísica: de Avicena a Heidegger, BAC, Madrid.

Maravall, J. A. (1989), «I pensatori spagnoli del secolo d'oro», en L. Firpo (ed.), Storia delle idee politiche, economiche e sociali, vol. III, Utet, Torino, 611-693.

Nys, E. (1922), «Les jurisconsults espagnols et la science du droit des gens»: Revue de droit international et de législation comparée 14, 360-387.

Rímini, G. de (1522), In librum secundum Sententiarum, Venetiis.

Rommen, H. A. (1948), «Variaciones sobre la filosofía jurídica y política de Francisco Suárez»: Pensamiento 4, 493-498.

Sabine, G. (2006), Historia de la teoría política, FCE, México.

Suárez, F. (1856) De Legibus, en «R.P. Francisci Suarez e Societate Jesu Opera Omnia, t. $\mathrm{V} »$, (apud Ludovicum Vivès, Parisiis).

Vecchio, G. del (1950), Lezioni di filosofia del diritto, A. Giuffrè, Milano.

Walkers, T. A. (1899), A history of the Law of Nations, Cambridge. 